\title{
Technology transfer in the construction industry
}

\author{
Petri Uusitalo $^{1}$ (D) $\cdot$ Rita Lavikka ${ }^{2}$ (D)
}

Published online: 1 August 2020

(C) The Author(s) 2020

\begin{abstract}
The demand for affordable, high-quality homes and premises has increased as society has evolved. Construction companies have shown that an industrialised housebuilding (IHB) platform strategy is an effective way of meeting exacting customer requirements. We decided to apply a managerial perspective and consider the IHB platform as a technological solution when investigating technology transfer (TT) in a construction context. Drawing on a meta-analysis of the literature and a qualitative case study at an IHB company, this work examines how two construction companies participate in TT. The results show that the IHB platform strategy can help a company overcome uncertainties associated with the TT process. Furthermore, the platform strategy supports the transferability of IHB to different markets, which, in turn, provides unique opportunities for companies from other contexts to enter the construction market. Our findings also revealed that CEOs from three construction companies were not only interested in TT due to potential profit improvements, but also considered how the process could benefit their employees and the community. This may be a result that is specific to Nordic culture or insight into a unique characteristic of the broad construction industry. This study contributes knowledge to the scarce research field of TT in a construction context. It provides evidence for how further cases of TT may disrupt the construction industry in terms of new business models or companies from the diverse field entering the market.
\end{abstract}

Keywords Technology transfer · Industrialised house building · Construction industry

JEL Classification $\mathrm{L} 74 \cdot \mathrm{O} 31 \cdot \mathrm{O} 32 \cdot \mathrm{O} 33 \cdot \mathrm{O} 34$

Petri Uusitalo

petri.uusitalo@ltu.se

Rita Lavikka

rita.lavikka@vtt.fi

1 Department of Construction Management and Building Technology, Luleå University of Technology, 97187 Luleå, Sweden

2 Smart Energy and Built Environment, VTT Technical Research Centre of Finland, 02044 Espoo, Finland 


\section{Introduction}

The answer to the question "Why should construction companies be interested in technology transfer (TT)?" is multifaceted. First, it is well known that TT can improve the competitive advantage of a company (Baughn and Osborne 1989; Porter 1980). In addition, TT is a vital component for economic development (e.g., Mansfield 1968; Schumpeter 1928) and pivotal to advancing both society (e.g., Foster 1962; Merrill 1972) and social welfare (e.g., Chatterjee and Ireyes 1981; De Laet and Mol 2000; Rogers 2010). Moreover, the diverse challenges currently facing society, e.g., demographic shifts, intense urbanisation, ambitious climate goals, and maintaining high employment levels, will inevitably also affect the construction sector (Brege et al. 2017). As a consequence of these driving forces, the demand for increased construction of homes and premises is becoming increasingly apparent. These factors, especially urbanisation, have resulted in the global construction industry hitting an all-time high of 1.39 trillion USD in 2018 (Deloitte 2019). Hence, a considerable rise in TT within the construction sector can be expected during the next decade.

Swedish construction companies have responded to the aforementioned societal challenges by developing an industrialised way of working, commonly referred to as Industrialized House Building (IHB) (Johnsson and Meiling 2009). These IHB companies aim to organise their business around total deliveries structured into platforms (Jansson et al. 2014; Johnsson 2013). However, IHB development around the world has lagged behind what has been achieved in Sweden. As a result, Swedish IHB companies have realised that the IHB platform is a competitive advantage when entering new markets. This is a novel approach, as construction projects are unique in the sense that each project is governed by a complex set of requirements that are defined based on-site- and country-specific circumstances (e.g., Kiviniemi and Fischer 2004). In other words, complex contextual understanding is generally a strict prerequisite for the success of a construction company in a new market.

The technology that IHB companies are transferring is the product platform, which is characterised by a high degree of standardisation in materials, processes, and predictable supply chains. This allows the company to offer houses in selected niche markets (e.g., Jansson et al. 2014; Johnsson 2013), and the standardisation is crucial to managing the complexity and uncertainty associated with the fragmented industry. The platforms of some IHB companies are ready for TT because they have reached a tipping point in terms of development and refinement. Hence, construction companies can potentially gain a competitive advantage by investing in this technological innovation, especially as product platforms have often been overlooked in the construction industry (Goodier and Pan 2012).

Although TT has been previously studied in the construction context (e.g. Bakuli 1994; Ofori 1994; Devapriya and Ganesan 2002; Ganesan and Kelsey 2006; Waroonkun and Stewart 2008), the focus has been on developing countries and the transfer of managerial knowledge and skills and not so much on technology itself.

To the best of our knowledge, this study is among the first attempts at understanding house building as a technology and how an IHB company addresses TT. This paper argues that construction companies should take an interest in TT due to its diverse (e.g., Krugman 1979) business and societal benefits, such as new knowledge, technology and increased standard of living. Moreover, TT can also lead to market disruption, as it enables companies from other fields to enter the market through investments into new technologies. The present study was guided by the following research question: 
RQ1 How do house building companies participate in technology transfer?

Accordingly, this paper provides new insight on TT for the construction industry by presenting how a platform strategy can be linked to TT. The research question relates to a case study in which one IHB company was studied both retrospectively and at present. Based on the results of this case study, we argue that IHB companies pursuing a platform strategy have reasonable grounds for TT, through which they can potentially explore expansion to other markets. The maturation of the construction industry corresponds with a higher possibility of non-construction companies entering the market through TT, which suggests that the platform strategy is both an opportunity and a threat for the industry.

This paper is structured as follows. We first establish a theoretical basis on TT as a starting point for the empirical case analysis. Next, we describe our research methodology, which included both a qualitative meta-analysis of the literature and a case study. We then describe the findings from our case study and conclude by discussing the implications of our research and outlining reasonable future research endeavours.

\section{Literature review}

Given that TT has been identified as a crucial part of solutions to developmental problems such as intense urbanisation and climate change, it is surprising that so little construction research has focused on this topic. The current TT literature should be reviewed to get an understanding of how TT relates to the field of construction. However, as TT has been studied in numerous contexts and by researchers representing different disciplines, various definitions for TT exist. Hence, a qualitative meta-analysis of the current literature preceded the case study examined in the present research. The information gleaned from the literature review would hopefully reveal the distinct characteristics of the construction sector, and help format a research question for studying how TT can be applied in the field of construction.

TT is defined as an active process during which technology is transferred from one unit to another (Autio and Laamanen 1995; Bozeman 2000; Bozeman et al. 2015). Numerous scholars consider TT to be a complicated process that needs time to evolve (Agmon and Von Glinow 1991). Over the past years, TT has been conducted in many fields of science (e.g. Noh and Lee 2019), which has rendered TT-like most emerging fields - a highly fragmented discipline (Zhao and Reisman 1992). As a result, a wide range of terminologies is used when describing TT. Mansfield (1975) was one of the first economics researchers to study TT from an industrial perspective (Teece 2004). Economists view technology as an essential input for economic development (e.g., Krugman 1979); hence, TT is a significant factor for the development of both developed and developing countries (Mansfield et al. 1983). Economists have also stressed that TT should follow a geographical gradient (e.g., North-South TT) as well as be able to cross the development chasm (Saggi 2002; Teece 1977). Region-to-region dynamics (Reisman 1989), as well as TT between different industries and economic sectors (Cunningham et al. 2017; Zhao and Reisman 1992), have also been promoted. Furthermore, from a nation-state perspective, economists state that TT occurs on both the domestic and international level (Hu et al. 2005).

In the field of management, TT is viewed as a means to increase the competitive advantage, and subsequently, profits, of a company (Zhao and Reisman 1992). Furthermore, technology is considered as a company-specific asset which includes both 
tangible and intangible components. The terminology specific to this field has a certain degree of overlap with the field of economics because some management researchers have been trained as economists (e.g., Teece 2004). In addition to terminology related to the field of economics, management researchers commonly discuss interfirm (Wahab et al. 2011) and intrafirm TT (Malik 2002), how technology can be transferred to a wholly-owned subsidiary (Arora and Fosfuri 2000) or joint venture (Wahab et al. 2011), and the marketing, production and R\&D associated with TT (Hu et al. 2005). In light of globalisation, management research also has a strong focus on international TT, which describes transferring the capability and skills for manufacturing a certain product from a company in one country to companies in other countries (Baranson 1976; Chesnais 1986; and recently Teece 2017). This has led to a growing body of research on TT mechanisms (e.g., Autio and Laamanen 1995; Cunningham et al. 2017) and different transfer processes (e.g., Stock and Tatikonda 2000).

Anthropologists focus on culture (Foster 1962); as such, they discuss the role of TT in terms of cultural evolution (Merrill 1972) with particular emphasis on the advancement of society (Zhao and Reisman 1992). This rather broad view of TT tends to focus on technological development as changes in cultural and societal patterns (Zhao and Reisman 1992). Therefore, anthropologists generally concentrate on the adaption and diffusion of new technologies and how they impact the development of societies. For this reason, anthropologists use more general terms to describe TT, i.e., cross-culture transfer (from the cultural perspective), group, community, and village programs (from the institutional perspective) as well as rural, urban, and regional programs (from a geographical standpoint). Hence, most of the anthropological research on TT has focused on agricultural, medical, and educational innovations.

Sociologists are concerned with how TT influences social welfare rather than economic performance (Chatterjee and Ireyes 1981). They tend to correlate technology with innovation (Bozeman 2000) since most new ideas in the last decades have been technological innovations (Rogers 2010). Regarding terminology, most sociologists discuss technology in terms of diffusion, more specifically, centralised and decentralised diffusion (Rogers 2010), and the adoption of innovation.

Lastly, Kumar et al. (1996) presented diverse motivations for TT, which can be divided across six categories: economic; operational; strategic; social; global; and personal.

A closer look at each discipline's perspective on TT reveals a key set of shared variables that should be included in a conceptual model of TT (Fig. 1). First, there is always

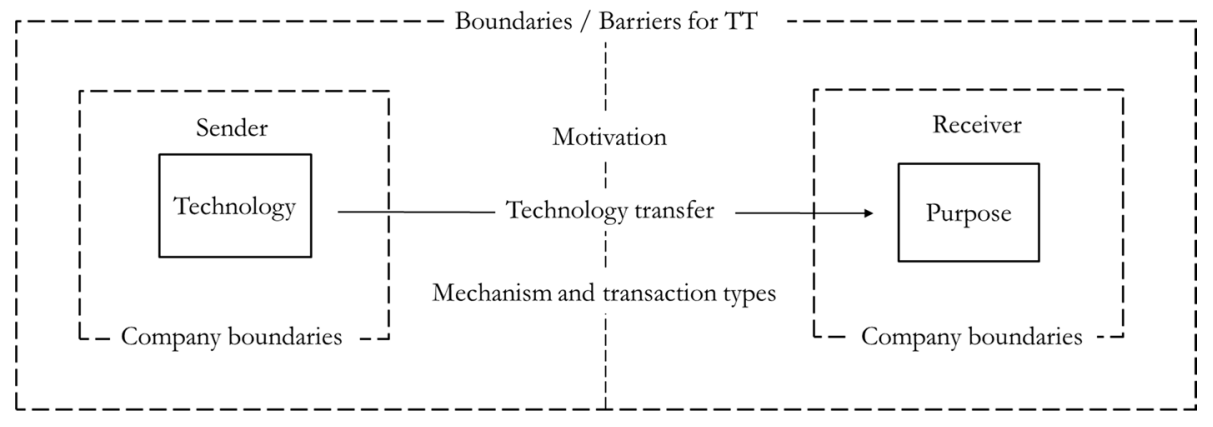

Fig. 1 The conceptual TT model 
a sender/owner and receiver of the technology. Second, motivation needs to exist on both sides. Third, both sides will undoubtedly encounter certain barriers to TT. Finally, TT is mediated by several transaction types and mechanisms.

\section{Characteristics specific to the construction sector}

This section provides an overview of the peculiarities associated with the construction sector, a topic that has been extensively discussed in the IHB literature.

Construction companies must develop and maintain competence in handling the shortterm variation that occurs in building projects, which are unique in the sense that they include temporary project organisation at the building site (Koskela 2000). Therefore, construction companies must establish broad resource bases if they are to be able to adapt their operations to the continuously shifting market situation. In other words, the creation of operational platforms that are ready to serve the entire market (Lessing and Brege 2015) will enable construction companies to employ a design and production strategy focused on flexibility. Hence, traditional construction companies usually make the strategic choice to prioritise flexibility over productivity as a source of competitive advantage (Winch 1998).

On the other hand, IHB employs a different strategy that has the following characteristics: prefabricated components are used to produce buildings; production systems are designed for specific niche markets; and production systems are maintained and updated to meet customer needs (Lessing et al. 2015). IHB firms generally focus on long-term planning and employee development to ensure that a steady flow of projects will support the stable production of prefabricated parts and that innovation will be inherent to each project (Jansson et al. 2014). Furthermore, the success of these companies depends heavily on the ability to integrate existing resources to the operational platform. As such, the platform is the foundation of established standards that ensure efficiency. Lastly, IHB companies strengthen their market position by investing in product development so that the operational platform is highly applicable to specific projects.

\subsection{Technology and construction}

The success of TT depends on whether technology-specific criteria have been fulfilled. The three main criteria that exist across various fields of science are product, process and knowledge (e.g., Howells 1996). Anthropologists and sociologists consider people and culture to be the fourth criteria of technology, as technology is delivered via products, processes, and people (e.g., Holstius 1995).

Therefore, the first question researchers should ask when studying TT in a construction context is "Can these three TT criteria be fulfilled?". Although construction applies a project-oriented approach, most of the processes are transferable from one project to another (Dubois and Gadde 2002). Moreover, knowledge about how unique projects are managed and completed is embedded in the processes and people. What is missing is a unique product, as pointed out by Gann (1996): "each house is treated as a pilot model for a design that never had any runs." Undoubtedly, a unique building or construction can be seen as a product, but as Gann emphasised, construction is, by nature, more of the creation of a prototype than a product (Gann 1996; Koskela 2003).

On the other hand, the strategy of IHB companies is centred around organising total deliveries into platforms. As such, the platform approach consists of four building blocks: 
(1) components, process, knowledge and relationship; (2) creating a product consisting of high degrees of standardisation of materials; (3) predictable supply chains; and (4) offering houses in selected niche markets (Jansson et al. 2014). Hence, the IHB platform represents a construction technology that could be transferred.

\subsection{Formulating the scope of the literature review}

Anthropological and sociological researchers tend to focus on the cultural and sociological aspects of TT. As such, they will describe people and the relationships between them, which means that their definitions of platforms will include processes, products, knowledge, people, and relationships. Researchers representing management and economic disciplines disagree with this view, as they argue that the technology to be transferred includes tangible and intangible assets, which implies that TT does not contain any cultural aspects. Thus, these researchers will always exclude people from their definition. This study applied the management perspective for the following reasons. First, it was an appropriate point of view as the research was based on an empirical study of managerial decisions related to TT in one IHB company. Moreover, the TT project is still under progress at the case company. The management perspective was also a relevant scope for the study as the research investigates how TT can advance the building industry, more specifically, how construction companies can cope with the increasing demand for sustainable housing.

\section{Research methodology}

This study - which includes the underlying aim of advancing the building industryemployed both a qualitative meta-analysis of previously published literature to identify concepts of interest and a subsequent empirical case study to demonstrate how IHB companies can apply TT.

\subsection{Qualitative meta-analysis}

Researchers undertake qualitative meta-analyses to develop novel interpretations that may provide a more in-depth understanding of a topic than what can be surmised by reading the primary literature (e.g., Ma et al. 2015). The main advantage of this methodology is that there is no need to analyse the entire body of literature, rather, when selected findings are contextualised appropriately, this approach can offer new insight into a topic (Schreiber et al. 1997; Levitt 2018). The coordination of diverse outcomes into a whole is, according to Finfgeld (2003), more substantive than trying to gain insight from the results of single studies.

\subsection{Selection of studies}

Given its broad applicability, Levitt's (2018) framework of methodological integrity was applied in the current paper to design the qualitative meta-analysis. According to this framework, the establishment of integrity includes two components, namely, fidelity to 
the subject matter (ensuring the relevance of identified research) and utility in achieving research goals (suitability of procedures in addressing research aims).

The meta-analysis was performed using five of the top journals in the field of TT research (see Cunningham et al. 2017), namely, The Journal of Technology Transfer, Research Policy, Science and Public Policy, R\&D Management, and Technovation.

\subsection{Procedure}

Articles were selected based on their relevance to the research aim of this paper, which is most accurately described through the research question "How do house building companies participate in technology transfer?". The literature review procedure is illustrated in Fig. 2.

After the completion of the analysis, two independent auditors (researchers with experience in the field of TT) checked the results by comparing the report with the conducted analysis. As in any form of qualitative research, the quality of a meta-analysis can benefit from credibility checks (Elliott et al. 1999); in this case, two independent auditors verified that the conducted literature review had a satisfactory level of credibility (Timulak 2009). The observations of the auditors were incorporated into the final meta-analysis categories after discussions with the researchers.

$\underline{\text { Input }}$

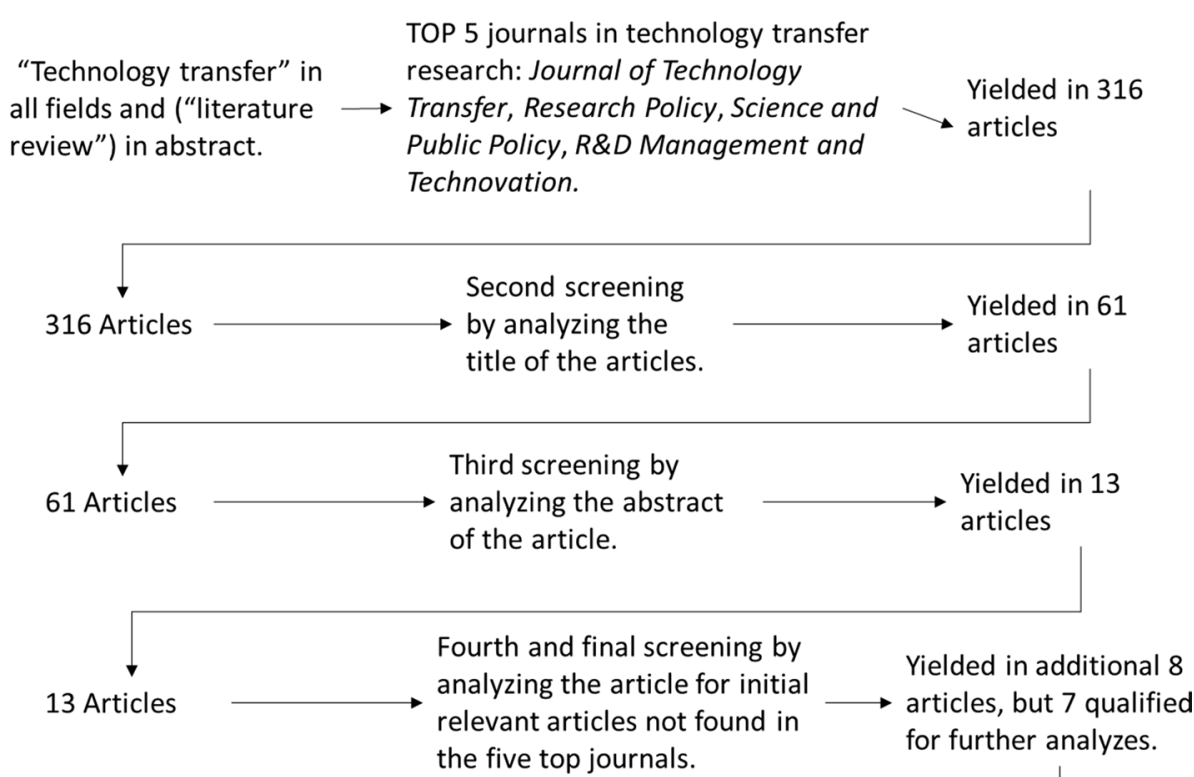

Total of 20 review articles were qualified for the review.

Fig. 2 The process used to identify relevant literature

\section{Extracting}

\section{Screening}


Fig. 3 The ten identified metacategories of TT
Barriers

Boundary conditions
Motivation

\section{Technology \\ Meta- categories}

Role of TT
Actors

Definitions
Transaction
types
Mechanism
Views

Screening by analyzing the title of the article Does the article title cover a broad spectrum?

Does the article title imply answering RO? Search for keywords

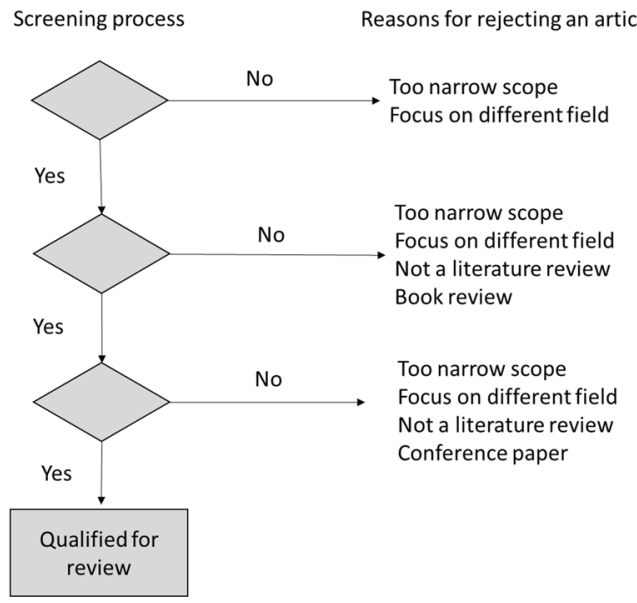

Fig. 4 Screening process

\subsection{Results of the meta-analysis}

A total of ten meta-categories were identified (Fig. 3), which were used to build the conceptual TT model (Fig. 6).

All literature reviews with a broad scope were included, and consequently, articles that did not fit the scope were omitted (Fig. 4). 
The search terms "Technology transfer" (applied to all fields) and "literature review" (applied to only the abstract) yielded 316 articles (Table 1). Only the search term "literature review" was applied to the Journal of Technology Transfer as the scope of the journal is TT.

The second stage of screening included an analysis of the titles of identified papers. After this stage of the screening process, 61 articles were identified as being relevant to the study.

Papers identified based on the title were then examined using the abstract to determine if they were relevant to the scope of the present study. In the third stage of screening, abstracts were searched for keywords such as "industry", "company", "construction", "manufacturing", "project", "longitudinal", “organisation", "manage", "management", "strategy", "product", "process", "productivity", "subsidiary", "competitive advantage", "case study" and "platform". This stage of the screening process identified 13 articles that qualified for further investigation. A literature review focusing on qualitative methods was also included to supplement the method applied in the present study.

During the fourth, and final, stage of screening, the researchers examined the chosen articles to reveal original articles that had not been found from the five screened journals (for example, Reisman 2005, paper in Omega). This final stage of screening yielded an additional eight articles, of which seven qualified for further analysis (Table 2). These articles also followed the detailed screening process (Fig. 4).

\subsection{Case study}

Since this research focuses on TT within a single company, the case study approach was used to obtain primary data. This approach can be considered appropriate based on Siggelkow's (2007) precepts for convincing case studies and because the case study provides insight into an unknown area to develop a theory (Bryman 2003). Moreover, the research design was in line with Kervin's (1992) guidelines as it applied various data gathering techniques, i.e., interviews as well as document analysis, during the in-depth investigation of one company. The research can be further categorised as descriptive based on the "finding out who, what, where, when, and how much" definition from Cooper et al. (2006).

While the case study approach can usually not be used to make generalisations, the method is nevertheless useful for building understanding about organisational activities, determining patterns and establishing theoretical connections between the factors being examined. Furthermore, the qualitative data obtained in most case studies have been shown to be more attractive to managers than the abstract variables and

Table 1 Stages of screening

\begin{tabular}{lccc}
\hline Journal & \multicolumn{3}{l}{ Stage of the screening } \\
\cline { 2 - 4 } & First & Second & Third \\
\hline Journal of Technology Transfer & 225 & 40 & 7 \\
Research Policy & 27 & 6 & 3 \\
Science and Public Policy & 11 & 6 & 0 \\
R\&D Management & 35 & 6 & 3 \\
Technovation & 18 & 3 & 0 \\
Total articles & 316 & 61 & 13 \\
\hline
\end{tabular}




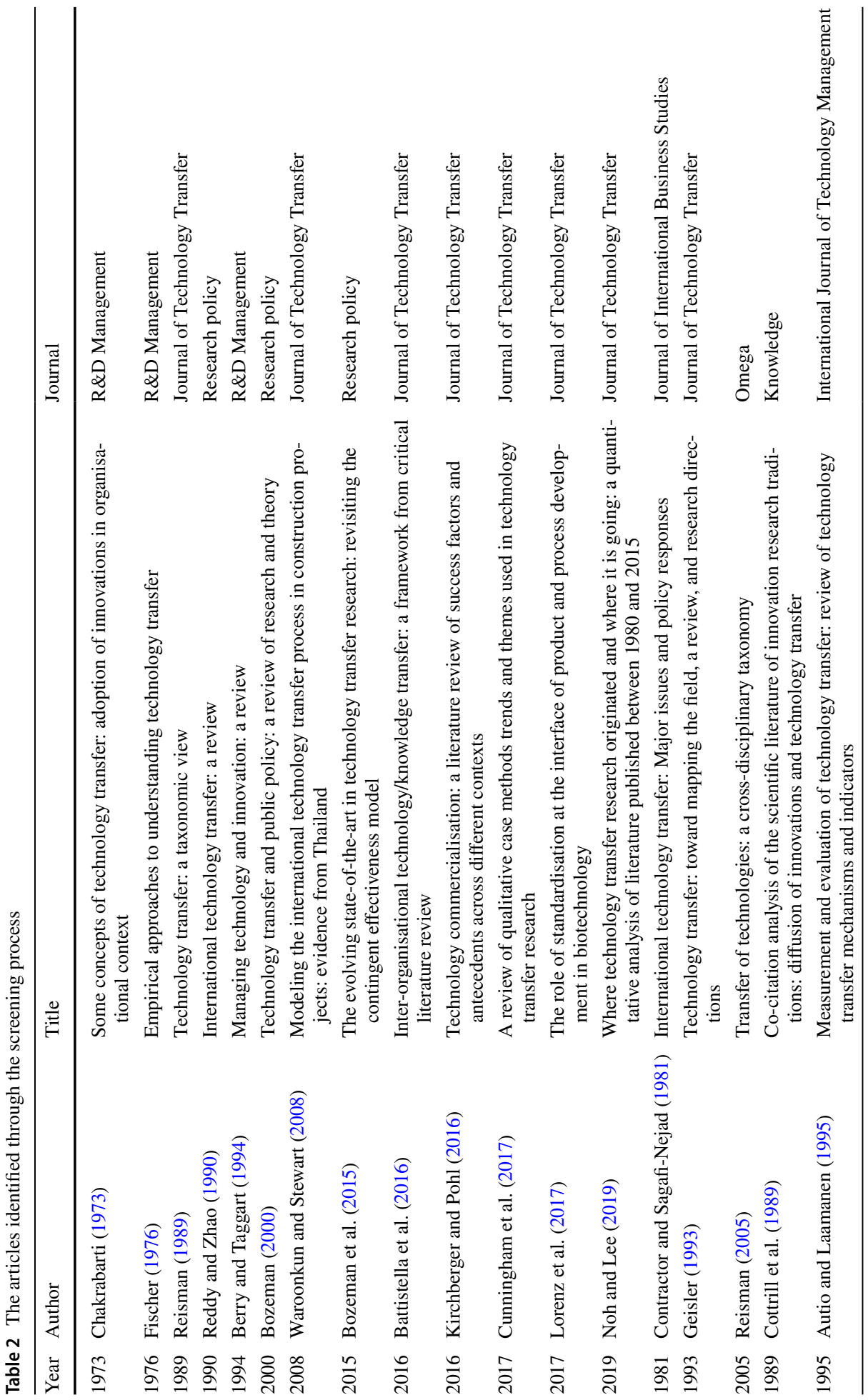




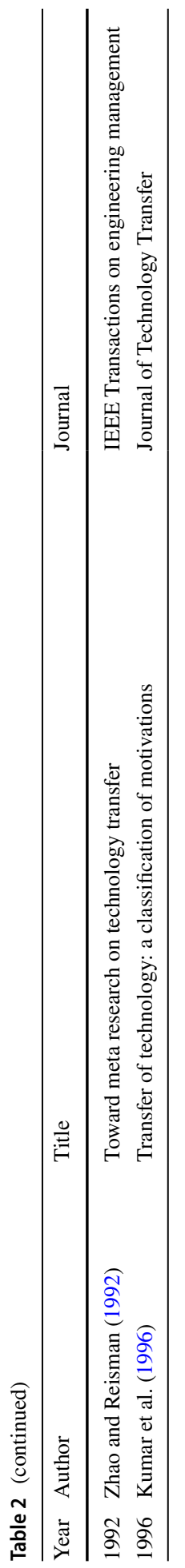


relationships that often characterise quantitative research (Bryman 2003). A further advantage of the case study method is that it can be used to generate hypotheses that will be analysed in subsequent studies (Yin 2013).

The case company is family-owned and manufactures industrially-built, multi-story modular timber buildings in Sweden using a unique 'volume construction' technology. The core of their current business is the industrial production of multi-dwelling houses made from wood from northern forests. By leveraging modern technology, the company is able to build attractive, high-quality housing quickly, safely, and costeffectively directly on site, with both private individuals as well as rental and tenantowner-owned apartments as customers. The industrial approach includes a high degree of flexibility so that the company can adapt projects to suit their customers' wishes. Hence, the end-products vary significantly in terms of architecture even though the method for producing house is highly standardised.

The company is considered auspicious because it has existed for over 90 years and has, in recent decades, transformed into an IHB company. Furthermore, the company has maintained detailed records throughout the transformation, which made it an excellent source of data for this type of study. The authors' good connections with the company made it possible to conduct in-depth interviews with relevant employees.

The first TT event was between the case company and its wholly-owned subsidiary (Company A), which produces prefabricated bathroom pods for hotels, nursing homes, and residential properties. The wholly-owned subsidiary aims to be lean and effective, yet offer their clients an opportunity to specify pod shape, floor material, ceiling material, glazed tiles, and bathroom accessories. The collaboration between these two companies started when the case company realised that their bathroom production could not fulfil the increasing demand. Instead of investing in production, the management decided, in 2015, to establish a subsidiary that would develop into a company specialised in the production of fully functional bathroom pods. Before the subsidiary was established, the case company sourced the bathroom floors from a sub-contractor. This sub-contractor has since been employed at the subsidiary.

The second TT event was between the case company and a newly established Finnish construction firm (company B) with no previous operations. In this sense, the receiving company does not have the historical burden of an established company (i.e., path dependency) and can hence be considered a tabula rasa. This company, established in 2017, aims to bring the case company's building system to the Finnish market by overseeing similar operations, albeit on a smaller scale. Both companies share the same values, which was a primary reason for their partnership.

The unit of analysis is the interaction between the case company and the two specific events (Fig. 5). However, the development of the case company also plays a significant role in understanding technology in construction and what has been transferred during the TT events. Therefore, archival data from the company was used to get a clear picture of the development process. The development began in 1993, which was the year in which the company started the industrial production of multi-story timber buildings from modules (Uusitalo and Lavikka 2020). The availability of relevant data spanning 20+ years provided an excellent overview of how the company developed a system for industrialised house building. To compensate for the uncertainty arising from retrospective data (e.g., recall effect), the interviews and archival data were crosschecked for consistency. 
Fig. 5 Case study design

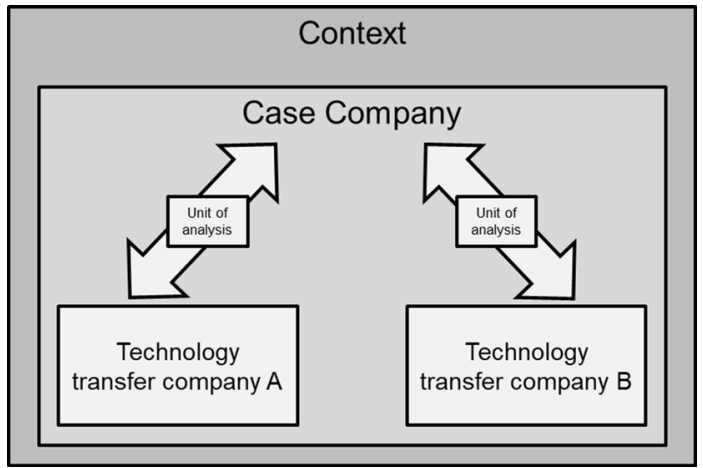

\subsection{Data collection and analysis methods}

The primary data collection method was in-depth, semi-structured interviews. A total of nine informants were interviewed, five of whom had worked at the company for over thirty years. Moreover, two of the interviewees had collaborated intensively with the case company over the last twenty years when guiding students in how to write academic articles and reports on the development of the company. The interviews were conducted between April 2017 and October 2019 and lasted approximately 1-2 h. Table 3 summarises the roles of the interviewees and what type of information was sought from each interviewee. The interview started with openly formulated questions and continued with more detailed questions about the development of the company to enable the interviewees to present their narratives. As pointed out by Guest et al. (2006), saturation can be reached after just six interviews. As with all aspects of qualitative research, the depth of the data is often more important than the numbers (Burmeister and Aitken 2012).

The chosen interviewees had substantial insight into the company's development. The number of interviewees remained low because one of the criteria for participating in the study was having worked at the company for an extended period of time. Another criterion was having had an active role in the company during its transition to an industrialised company. These criteria were applied to recruit a group of interviewees who could provide a broad view of the company's development during the period covered by the study. This targeted selection ensured that the interviewees could speak about the development of the company. As such, the interviewees had witnessed firsthand the changes in the organisation from a position that allowed them to understand the decisions that contributed to the company's evolution. Although the group of interviewees was small, their collective expertise and extensive involvement in the company meant their responses gave an adequate description of the changes that took place in the organisation. According to Romney et al. (1986), a small number of participants is justified when the participants possess a high degree of expertise on the research topic.

Of the 14 interviews, seven were conducted in pairs, with the two researchers selecting the interview questions through a collaborative process. Lundahl and Skärvad (2016) have suggested that the benefit of having two researchers conduct interviews is that while one researcher is conducting the interview, the other researcher can observe, make notes and ask follow-up questions. In a bid to minimise research bias, the researcher who had the least previous personal contact with the company was put in charge of leading the discussion. The interviews were recorded and transcribed, after which they were cross-checked 


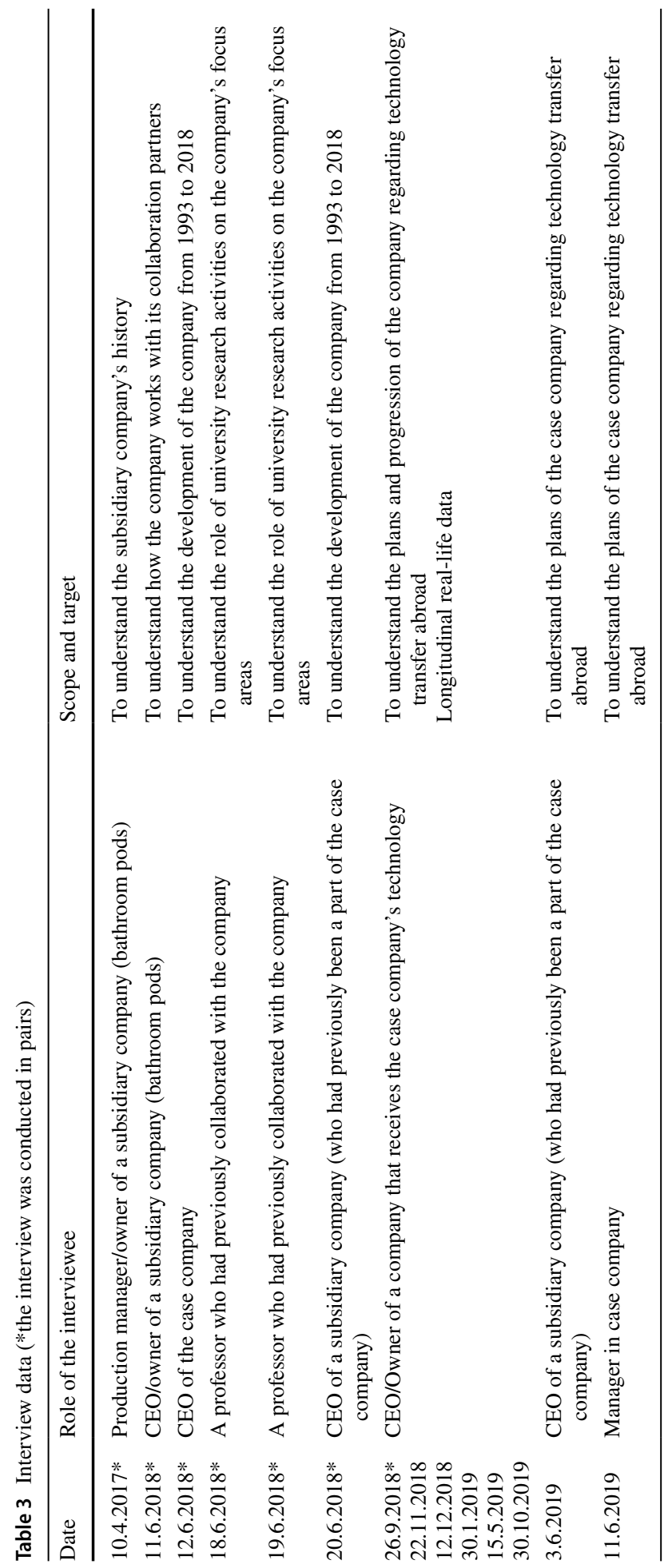


with the interviewees to ensure transparency, quality, and accuracy, as well as increase reliability and validity. An inductive approach was used when coding the interview material. This decision was made to ensure validity and avoid bias during coding, as the data required in-depth reading and re-reading. The inductive approach facilitated the identification of critical themes in the area of interest by reducing the material to a set of categories.

The case company is known for its close collaboration with academia, and several academic publications chronicle this collaboration. During the second part of the case study, the researchers analysed secondary data, which consisted of five article-based dissertations (Bergström 2004; Björnfot 2006; Höök 2008; Jansson 2013; Meiling 2010) published between 2000 and 2013 and a company history report (Westerlund 2009), through metaanalysis. These documents provided essential insight into the development of the company, and their inclusion in the research considerably strengthened internal and construct validity. Furthermore, the information provided in these documents can be assumed to be reliable because the interviewed university professors supervised the dissertations and oversaw the writing of the research reports. The professors commented on the meta-analysis results concerning the dissertations to improve the credibility of the analysis.

\section{Findings}

This section presents the findings of this study. First, the theoretical TT model is further developed based on empirical findings. Then, the two technology transfer events are discussed.

\subsection{Further development of the TT model}

The findings from the empirical case study were analysed according to the concepts presented in Fig. 1, the conceptual TT model, which had been developed based on the literature review. The empirical research identified how the case company developed a structured way of working that includes a product platform and standardisation. The main findings are compiled in Fig. 6, which illustrates how the case company participates in TT.

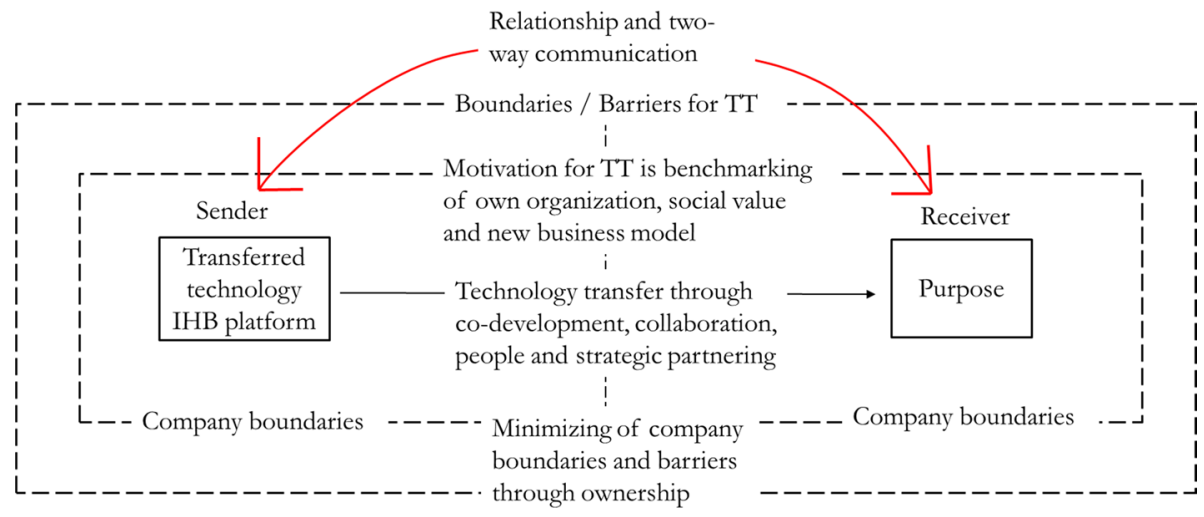

Fig. 6 Insight from the conducted empirical case study, presented using the previous model of TT concepts 
As illustrated in Fig. 6, the empirical research clarified: (1) what technology has been transferred; (2) motivations for TT; (3) what transfer processes are used and (4) how barriers to TT can be eased.

Based on the case study findings, the platform (bathroom pod and IHB) was the technology that was being transferred from one company to another. This result confirms previous reports that the TT process involves a complicated relationship between the partners (Wahab et al. 2011). The results also demonstrated that TT requires close communication between the sender and the receiver. However, contrary to Wahab et al. (2011), the findings imply that intra-firm TT demands higher levels of communication and involvement than inter-firm TT. A possible explanation for this finding could be that the actors involved in intra-firm TT have a better understanding of the technology, and therefore, could demand more information flow through communication. Furthermore, Malik (2002) proposed that actors involved in TT accumulate various competencies over time; hence, the process should be more significant for the company than the technology receiver, which entails extensive intra-firm communication.

The empirical case study findings also revealed that successful TT requires long-term commitment and the building of a healthy relationship between parties, which agrees with previous research (e.g., Malik 2002; Wahab et al. 2011). In addition, the chosen technology, along with its implementation, should be thoroughly developed and tested to reach a certain maturity level and maybe even achieve acceptance on the market. Technology transfer processes that do not meet these requirements may not be successful. Furthermore, as demonstrated in Fig. 6, the relationship (i.e., shared values) between the sender and receiver is pivotal to motivating the decision to participate in TT. In our case study, the CEOs of the case company, the subsidiary, and the receiving company all talked about the social aspect, which revealed that they shared common core value. For example, the CEO of the case company explained that the company must not forget to think about the people who will live in the houses, and the main part of their work is lowering the costs associated with owning a quality apartment. Another stressed that "you have to contribute to society, you have to understand the demands that society places on the property owner" [CEO Group subsidiary].

Regarding the Finnish construction context, both the government and society have pushed construction companies to transition to using more sustainable building materials (Bosman and Rotmans 2016). If the sociological aspects of construction are not accounted for, then there are no institutions to where technology can be transferred. This is an exciting finding when considering that TT in any industry is a managerial, strategic decision intended to improve competitive advantage and, subsequently, profits (Baughn and Osborne 1989; Porter 1980).

\subsection{Comparison of the two technology transfer events}

The bathroom pod TT event closely resembles how Stock and Tatikonda (2000) describe co-development. In their view, the relationship between the sender and receiver during codevelopment is characterised by a high degree of communication, co-operation, and coordination. The bathroom pod project was a joint $R \& D$ investment in which one of the owners of the subsidiary company assembled a group of experts from the case company to develop the product. The owner and product manager of the subsidiary company describe: "Then I brought in the competence that I considered we need. Then we ask the group if we need further competencies to get started. Finally, we had a group. We had all the competencies 
we needed in this group to be able to implement the process at the case company in a good way and develop a good product."

The decision to incorporate the supplier of bathroom pods into company operations indicates that the management at the case company appreciates deep supplier involvement in product or process development, which reflects the high level of organisational interaction found in a co-development transfer (Stock and Tatikonda 2000). The organisational boundaries between the sender and receiver were blurred, or possibly even eliminated, due to the case company's ownership of the subsidiary company. Hence, the sender and receiver work together, mainly as one integrated, albeit often ad-hoc organisation, to transfer and successfully implement the technology in the receiving organisation. The owner and production manager at the subsidiary company describes the transfer as: "That trip would never have happened if [the company] had not been there to support us with competencies in different areas. Good economic people have helped us. After all, they have supported us with advice, they [two owners] sit in the steering committee, so it has been a sounding board for us. They come up with good advice, also financially".

Stock and Tatikonda (2000) also mention that co-development may entail lengthy physical co-location of personnel from the sending and receiving organisations. However, in the case studied in this research, the new production facility of the subsidiary company was located close to the case company. Hence, it was not an immense problem for some of the personnel to visit both offices over the transition period, as joint resources between the case company and subsidiary were necessary to operations. A key player in this event was the production manager, as he was the one who moved from the case company to the subsidiary and brought IHB knowledge to the company. He elaborates: "After all, it was me who raised the issue that we cannot cope with the increased demand by using the "business-as-usual" approach. I was then commissioned to look at various alternatives. I saw the problem, was commissioned to solve the problem, found a solution, a product, and-at the end-it was me who asked the management if it is possible for me to enter as a partner in this" [Owner \& production manager of the subsidiary].

The other TT event - between the case company and company B-resembles a more collaborative hand-off approach to TT than co-development. This TT event was motivated by the case company becoming very successful and having ambitions to expand. What differentiates this TT event from the one described above (co-development) is the IHB platform development. In the second TT event, the case company actively transferred a product to a new company. As such, this example of TT can be considered more of a business transaction than developing a new business model.

Regarding the co-location of personnel, the collaborative approach also includes extensive and lengthy co-location of employees from both companies, even though they are in different countries. However, as the CEO of the receiving company explained: "We will have a personnel exchange program, where our employees will work at the case company for a while, so they learn how things work." This quotation demonstrates how the organisational boundaries of both companies were also blurred based on how the collaborative approach was managed. More specifically, the sending and receiving companies work together, including the temporary transfer of personnel, to successfully implement the technology in the receiving organisation.

In both TT events, the same product (IHB platform, including supporting elements) was transferred although one event represents internal TT while the other event represents external, international TT (Table 4). This demonstrates that the case company has developed one strong core competence as a competitive advantage-experience in industrialised building, organised into a product platform. Both cases of TT included the development 


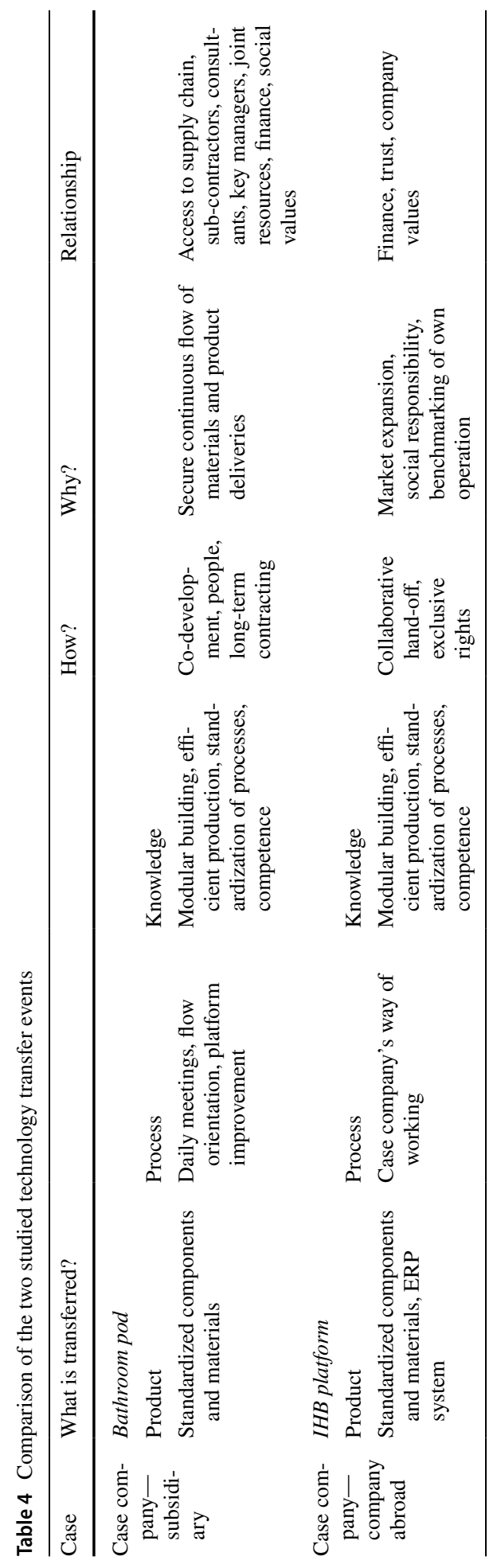


of strong relationships between the sending and receiving parties. It seems that trust aids the TT, as this characteristic increases the sending organisation's willingness to help the receiving organisation understand the newly gained knowledge. In other words, trust "reflects the belief that the word or promise of a partner is reliable and that the partner fulfills the obligations in the relationship"' (Inkpen 2000:1027). A relationship of trust readily forms when the partnership mutually benefits both parties. The sender is committed to the relationship with time, resources, and capital. However, TT can only succeed if the receiver is motivated and capable. In TT, receiving organisations gain confidence, when they feel that the sending organisation is willing and open to sharing insight, which is pivotal to building trust. The empirical case study covered in this research revealed another aspect that can secure trust between parties, namely, partnering based on ownership of the receiving company. This type of dynamic sends a strong message that the sending organisation is committed to the partnership as the success of TT will directly affect the interests and performance of both companies.

\section{Discussion}

The next section will further present and discuss the empirical findings in terms of the conceptual TT model (Fig. 6) and its different constructs. The findings are presented from the sender's perspective and focus on how IHB as a technology can be transferred. The findings thereby provide insight into how the adoption of IHB in the construction sector can be promoted.

\subsection{Construction companies participate in technology transfer to benchmark their performance, provide social value, and create new business models}

"This is about wanting to change the construction industry" was the response of the subsidiary's CEO when asked about the reasons for starting TT collaboration with a company in another country.

Many drivers can motivate TT, and accordingly, motivation also depends on the desired outcome. The case company has always strived to change the construction industry. When the building codes changed at the beginning of 1994, the company decided to try and produce houses in a factory. As a result, they moved their building sites into a factory environment and tried to do as much of the building as possible in the factory.

The CEO of the subsidiary company explained the company ambitions in the following way: "This is where we believe there is great potential when it comes to building in a smarter way than what is traditionally done. We have been working on that since the mid90 s, with an attitude of trying to change the construction industry, and I would like to say that we have already done a certain part. At the same time, we feel that there is a lot left to do".

The company has previously stated that social responsibility is a key motivator in striving to develop the company and the industry. For example, the CEO stated that the company could achieve better margins if it had the sole purpose of being profitable. However, this is not the case, with the CEO explaining "If we can lower prices and produce housing at a low cost, we will make a difference for many people, and that is one thing that is very, very important. 
This responsible attitude is visible throughout the organisation, with some of the senior managers providing anecdotes of how the business is not only about making a profit: (1) "Because today you are not just building housing, today you have to be a community builder. So you have to contribute to society" [Executive Vice President of the subsidiary] and (2) "What we are visionary about is that we can help it be built for more people" [Lean manager].

What the company has developed throughout the years is the IHB platform. Over time, members of the company began to understand that they could use their knowledge of IHB to their advantage, as the CEO of the subsidiary company pointed out: (1) "But what has come to light is that our main business idea is to sell houses. However, since there has been so much interest in the company, we developed a method first to develop projects and later build them, which provides value."; and (2) "The basic idea is that we think we can sell the knowledge we have; we sell houses, but we can also sell the knowledge we have, which is the basic idea in this."

In addition to the motivations that are linked to core company values, the company also participated in TT due to more practical reasons. For example, the CEO explained the decision to co-operate with a Finnish company as follows: "The reason is that we need this Finnish project to benchmark ourselves in how to sell our technology." As the company will partially shift its focus to how the IHB platform can be sold and transferred, the lean manager said: "We are in the process of aligning our organisation just for this technical transfer". Furthermore, the lean manager then switched to discussing how the company wants to advance the construction sector of other countries, stating "what we offer is progress in a short period of time. If it has taken us 25 years to get where we are today, we might be able to make the same trip with a customer in 3-5 years."

\subsection{IHB platform as a technology}

\subsubsection{Standardisation of components and materials}

In the early 1990s, the house building market experienced a crisis, and many companies went bankrupt. At this point in time, the case company was operating in the same way as other traditional construction companies, i.e. they "built everything." To be competitive in the new market situation, in the mid-1990s, the case company decided to change how they build houses radically. As a result, a large part of the on-site production was moved into a factory environment. "We understood that the market would recover in the metropolitan areas with the university cities, and if we wanted to compete in those markets, we had to be more industrial," describes the CEO of the subsidiary company. The decision was also guided by regulatory changes in Sweden in 1994, which, among other things, allowed the building of multi-story wooden houses. The shift towards industrialised construction started with the development of the product platform that the company still applies today. The CEO describes this transition in the following quotation: "In 1992, we decided to move most of the on-site work inside a factory and started to develop our platform. From 1994 until today, there have not been so many dramatic changes".

The company started to standardise components into a predefined platform, simultaneously shifting from on-site construction to offsite manufacturing. This meant that the company had to cope with both horizontal (between different actors in the building process) and vertical discontinuities (managing sub-contractors and suppliers in the respective value 
chains). All of the managerial activities had to consider these two discontinuities since the case company started to combine on-site construction and offsite manufacturing.

The standardisation of components progressed in small steps through successive projects, as the company gradually refined the platform. This platform development process, i.e., building a platform while seeking opportunities for further development, helped the company focus on standardisation in the late 1990s when the company shifted towards the open building market. The CEO of the subsidiary company describes this point in time through the following quotation: "The more standardised we become in our technical solutions, the more flexible products we could deliver". Hence, the company further developed its existing resources and continuously developed the platform for new building projects, i.e., "The next time we competed to engage our platform, we made it a bit harder to ourselves than what we did in our previous project" [CEO of the subsidiary company]. The company strategy transitioned from the standardisation of components to the standardisation of work and processes with an overarching goal of minimising variation in production. This transition also marked the start of the company's co-operation with academia, culminating in a $\mathrm{PhD}$ project on how problem-solving in construction can reduce defects, enhance learning, and improve accuracy in module prefabrication (Meiling 2010). By implementing this new knowledge of process control in the standardised manufacturing and design processes, the company became more resistant to internal and external variations. The links with academia resulted in Jansson (2013) studying standardisation work in the company. He would later demonstrate that standardised engineering design work consisting of both standardised components and standardised processes can be implemented into a platform. Some years later, Lorenz et al. (2017) found that standardisation increases the success of TT.

\subsubsection{Standardisation of processes through lean practices}

Lean production practices have also largely impacted the development of the platform, and lean thinking has been a central element in the evolution of the company since 2002. Höök (2008) provided insight on how the company was able to stabilise variation in production and increase factory output by applying lean practices. A lack of standardisation, company strategies coming directly from upper management, and employee loyalty were the main problems that initially motivated the company to apply lean thinking. In 2009, the company hired a lean consultant and embarked on a four-year lean implementation program to improve production processes with the goal of increasing production capacity by $30 \%$. The program improved the stability of the process, quality of internal work and proportion of on-time deliveries. The CEO of the subsidiary company discussed the role of lean thinking at the company as follows: "We wouldn't be able to do this at all if we weren't a lean organisation".

Furthermore, the collaboration with a lean consultant was pivotal to the company developing a capability to systematically handle daily processes across every part of the organisation. The lean culture also allows the sales department to focus on their role, which is making customers feel that they are getting a unique, high-quality home: "In actual sales work, you cannot set up a LEAN plan and say that now we treat the customer in only one way. Instead, every customer and each project is unique. You do not do business with companies. You do business with people. But, on the other hand, we feel confident anyway because we have already decided on a standardised process before signing the contract" [CEO of the subsidiary company]. 


\subsubsection{Supporting the development of the product platform}

The case company made many significant investments in the product platform during its development. This strategy can be considered quite risky since the business of building houses based on an engineering platform is only competitive in specific niche market segments. As such, the case company has always needed a clear perception of the customer needs. Furthermore, the company has extensively supported clients and developers in producing unique buildings, which has helped both develop relationships and the product platform. The CEO of the subsidiary company described this task as: "We needed to seek clients and housing developers before they contact the consultants to tell them about our way of working and the restrictions and benefits of our platform" [CEO Group subsidiary]. In other words, the management understood that it was important to foster relationships with potential developers, clients, and, above all, architects, as they are the gatekeepers in the process of developing building projects.

\subsubsection{Technology transfer through co-development, collaboration, and strategic partnering}

The case company has been working closely with a local university for over 25 years (since 1993), "Co-operation with the university was part of a long-term plan. However, much of the co-operation has come as a market requirement for our development" [CEO]. The company mainly entered into a collaboration to convince the building market of their product. The university became a "brother-in-arms", and-over the years—various academic studies have been undertaken to introduce new technologies, verify the performance of the building solutions, and validate the product as viable and safe. The primary long-term benefit of this strong relationship has been gaining a scientific perspective on the process and product development.

Respected and influential architect companies have also been crucial strategic partners for the case company. In the 1990s, the case company experienced problems in winning orders as the Swedish building specifications and published tenders did not match the company what the company was producing. The CEO explains the situation as follows: "For the whole 90s and early 2000s, it was about showing that this is a better way of building". However, a decision to incorporate talented architects in the early design phase enabled the company to adapt their parameters to market demands. Hence, the company secured access to critical resources by investing in the development of strategic relationships.

Attracting highly skilled members of the local workforce is another of the company's core values: "One of the strategic goals is to be the top employer brand in the business" [CEO]. The company has an outspoken human resource strategy to be a successful company in both the short- and long-term. For example, the company has stated that it needs to build an attractive work environment to secure the flow of employees and, at the same time, support the local community, with the CEO emphasising that "it is important to treat the customer and contractors the same way as if they were employees. Even if a customer misbehaves, it's important not to burn bridges because they may someday turn out to be an important customer". This proves that being proactive is critical in the construction sector, as well as most other industries. The case company has achieved considerable success by listening to customers, developing and managing diverse professional relationships, following changes in the business environment, and securing access to key resources (both capital and human). These factors have also significantly contributed to platform development. 


\subsubsection{Internal technology transfer}

Industrialised construction is currently well known and widely accepted in Sweden. Multiple years of increased demand for the company's products resulted in several decisions to speed up production pace and reduce production bottlenecks. One of these was the decision to create a wholly-owned subsidiary that builds and installs complete bathroom pods that are compatible with the existing volumetric elements. The establishment of the subsidiary in 2015, along with the subsequent strategic partnership between the two companies, was the first significant TT event in the company's history. At the centre of this TT, the event was one of the case company managers (later to be one of the owners of the subsidiary), who initiated the bathroom pod project to cope with increasing demand. The manager used a panel of experts to identify and manage issues concerning the new product. In this way, knowledge and expertise from different departments were gathered and compiled to create a business model and associated processes for the development of a prefabricated bathroom pod. When the opportunity arose, the manager who had first started the bathroom pod construction project became one of the owners of the subsidiary. The manager was able to convince some of the production personnel at the case company to move to the subsidiary and continue working in bathroom production. It is important to note that the subsidiary had access to the case company's support functions (e.g., finance, logistics, planning).

This example of TT benefited the case company as substantial investments, which would have been used to overhaul the bathroom production at the case company, were avoided, and the subsidiary was able to immediately begin the efficient production of prefabricated bathroom pods to meet contracted orders. The fact that the subsidiary had access to case company resources helped with the streamlining of processes and ensured continuity for both companies, as the case company was now dependent on the pods produced by the subsidiary. The owner and production manager of the subsidiary described the TT event as: "This was to ensure that the focus would be on bathroom pods and to ensure that they would get bathroom pods".

\subsubsection{External technology transfer}

Since the start of co-operation, the case company and company B have enjoyed a tight relationship built on trust. From the first contact in 2017 to the first project delivery in autumn 2019, the case company has considered collaboration and long-term thinking as the critical ingredients to success. "I think you have to be long-term in this. I think there is a risk that you underestimate the work and effort required to get started on the type of business we have. Therefore, you have to endure and understand that it will take some time, but still do it as quickly as you can. But I think the main challenge is being persistent" [CEO of the subsidiary company].

The goal of the studied external TT was sending another company the know-how and means to run a company similarly as the case company, just on a smaller scale. More specifically, the Finnish company received the production system, including everything necessary to run projects (e.g., project coordination, planning, and supply chain management), the enterprise resource planning (ERP) system, and leadership. This was critical to establishing a steady flow in the factory, with the CEO of the subsidiary stating: "When we get a flow to work, then the whole system will work". The case company also supported the receiving company in procuring the right type of equipment and machinery for the 
production facility. Furthermore, the receiving company needs to clearly understand how the work is performed at the construction site (e.g., assembly of volumetric elements, construction site management). Hence, the case company was responsible for ensuring that the receiving company had all of the components, as well as the competence to "fit" them together. Based on this description, it could be assumed that the entire company culture is being transferred, but the CEO of the subsidiary company argues otherwise: "I would not say that the culture that we are going to transfer, instead is more of our way of working, our methods and processes that are transferred." He concludes "in this context; when we talk about TT and what it is, you have to go back and think that it is long-term, and it is the whole thing that is the key to success. I want to point out again that no individual part is the key to success, but success is based on making the whole thing work together".

\section{Conclusion}

This is among the first times that TT is discussed in the context of construction. This study identified a tangible construction-specific product, IHB, to allow research into how technology is transferred in the construction sector. Although Waroonkun and Stewart (2008) discussed TT in construction projects, their study concentrated on how a project can be transferred.

In contrast, the present study regards a project more as a prototype than a product (Gann 1996; Koskela 2003), and adopts the view that each project creates a unique building. Furthermore, Kirchberger and Pohl (2016) argued that technologies need to be integrated into products that are sold if they are to generate value for society and profit for the company. Therefore, from our perspective, the research of Waroonkun and Steward (2008:668) focused more on knowledge sharing than TT. As they describe, "TT has been defined as when all types of knowledge relating to the construction field (e.g. design, construction process, material use, equipment utilisation, etc.) are transferred from a foreign party to a host party".

TT in construction has also been discussed in the context of developing countries (e.g. Bakuli 1994; Ofori 1994; Devapriya and Ganesan 2002; Ganesan and Kelsey 2006). The previous research has added insights into how collaboration with foreign construction companies has generated significant benefits to less developed countries. The developing countries have benefited in training, project formulation, design and implementation, and moved towards more sustainable construction.

However, the research conducted in the context of developing countries (Bakuli 1994; Ofori 1994; Devapriya and Ganesan 2002; Ganesan and Kelsey 2006; Waroonkun and Stewart 2008)) focus on transferring knowledge and skills, construction techniques, organisational know-how and management systems on a country-level, whereas this research focuses on transferring a tangible product between companies.

This study aimed to identify how TT occurs in the construction context. The study approached this managerial issue through a qualitative meta-analysis of TT literature and a case study of an IHB company. The qualitative meta-analysis revealed that a universally accepted definition of technology comprises three constructs: product; process; and knowledge. Interestingly, these are the same constructs that comprise an IHB platform. Therefore, an IHB platform should be considered a technology that can be transferred between either two construction companies or a construction company and a company from another industry. This can be taken to mean that TT will be an essential part of future business 
models, as well as a way to gain competitive advantage through market disruption. Therefore, TT literature should have a sharper focus on how product platforms can be applied in construction. Also, TT can be an effective way for construction companies to move away from the current economic model towards a more resource-efficient one, and "bringing buildings into the circular economy", as desired by the European Commission (2020).

The evidence from this study highlights that investments into product platforms can benefit TT in construction. Furthermore, the empirical case study revealed that successful TT in the construction context requires a strong relationship between the participating companies. An explicit limitation of this study is that it is based on a single case (with two TT events), which is considered from the managerial perspective. The single case approach was chosen due to a need for in-depth information on specific company decisions, which is pivotal for drawing conclusions about company strategies. However, as the present study covered a single case, future research should investigate other types of construction companies - both Nordic and international - to verify the findings of our study. Apart from managerial decision-making, cultural and social aspects also affect the transferability of the IHB platform, which means that TT researchers could also adopt a socio-technical view in light of the increased demand for sustainable housing. To provide further insight into TT within the construction sector, we intend to study TT from the receiving company perspective.

Based on our findings, construction companies interested in implementing the IHB platform strategy through TT should consider the following guidelines:

1. Both companies are motivated to participate in TT.

2. The receiving company should build a strong relationship based on trust with the technology sender.

3. Every TT project includes a long-term commitment.

4. The involved parties should work to minimise organisational boundaries, which entails being prepared to sell a portion of the company to the sender to build a partnership.

5. Technology is a collection of interconnected constructs that must be handled as a whole.

Innovative technologies are always disruptive, which means that an increase in TT within the construction sector could redefine the market through internationalisation and the entrance of companies previously not associated with construction, both of which will make the competition even more fierce.

\subsection{Company-level implications}

The decision to expand an existing business is often financially driven. However, this research showed that the CEOs of a case company, its wholly-owned subsidiary, and a foreign company seem to have an additional reason for participating in TT. For these managers, the driving factor for transferring technology was not only better profits but also improvements to employees and the community. Even though competition in the construction sector is mainly based on price, it is surprising that social aspects have such a strong influence on how this specific company operates. The societal structure of Nordic countries, i.e., all of these countries are considered welfare states, may likely explain this finding. People see affordable, high-quality living as a fundamental right, and this peculiarity may have caused the studied managers to focus heavily on corporate responsibility. In addition, the case company had made bold decisions to reach its formidable market 
position, and the managers probably looked for partners with similar values when considering expansion.

The topic covered in this research is elaborated upon by Uusitalo and Lavikka (2020), who also chronicle how the case company has evolved during the years. Similar to the present research, their findings stress that all of the parties involved in TT should share the same vision and goals. We feel that the findings demonstrate that there is no optimal way to conduct TT, as this process is highly context-specific and depends on the maturity of the technology being transferred. Therefore, companies (both the sender and receiver) must thoroughly understand what is being transferred, with a predefined product easier to transfer than a vague concept. This characteristic makes TT particularly challenging in the construction field, as businesses in this sector rarely provide a defined product. This is because construction businesses have a scarce customer base, are heavily influenced by local regulations, and are increasingly expected to provide unique solutions.

For this reason, construction companies are not used to conducting TT in both directions. Hence, construction companies must build new capabilities if they are to handle TT successfully. This may explain the low degree of digitalisation (e.g., use of Building Information Modeling or robot-facilitated building) in the construction sector. As was shown in the empirical case study, TT binds resources which construction companies may need to exercise flexibility for competitive advantage. As such, long-term commitments between companies are rare, and will severely hinder TT in the sector.

\subsection{Industry-level implications}

When we consider the findings on the industry level rather than on the company level, it seems that TT may significantly impact the construction market. For instance, companies in foreign markets now have the opportunity to take a large technological leap by investing in the IHB platform. This, of course, requires that these companies can successfully implement this technology. As mentioned by one of the interviewed CEOS, what it took the case company two decades to build may now be possible for other construction companies to implement in a much shorter period, e.g. 3-5 years. This will also enable companies that effectively leverage the IHB platform to gain access to new markets and disrupt local construction markets to gain market share. In addition, the maturity of the IHB platform means that companies from other industries (electronics, retail, etc.) may be able to access the construction market. These companies have superior capabilities in other areas of business, but not in building houses.

One example could be Amazon, an American multinational technology company. It is considered as one of the Big Four technology companies, along with Google, Apple, and Microsoft. Amazon has recently invested in a home-building start-up Plant PreFab. This decision to move into prefab construction could be seen as a stepping stone for the company to later invest in an IHB platform. Due to extensive expertise in technological innovation and mass scale, Amazon-equipped with an IHB platform - may threaten the existing construction companies as Amazon could compete on various levels (i.e., price, quality, and reliability). This type of competition could be positive for customers, as the potential increase in competition would drive prices down.

Acknowledgements Open access funding provided by Lulea University of Technology. The research was conducted as part of the Aalto University's research project "Building 2030 - industrialised construction", which is funded by 16 companies from the construction sector. The research has been financed by Aalto University's Digital Disruption of Industry (DDI) project, which is funded by the Strategic Research 
Council of the Academy of Finland. The Finnish Science Foundation for Economics and Technology also financed the research. The authors would like to thank Luleå University of Technology and the Department of Construction Management and Building Technology for their support.

Author contributions PU: Conceptualization; Methodology; Supervision; PU and RL: Data curation; Formal analysis; Funding acquisition; Investigation; Project administration; Resources; Validation; Visualization; Roles/Writing_original draft; Writing—review \& editing.

\section{Compliance with ethical standards}

Conflict of interest The authors declare that they have no conflict of interest.

Open Access This article is licensed under a Creative Commons Attribution 4.0 International License, which permits use, sharing, adaptation, distribution and reproduction in any medium or format, as long as you give appropriate credit to the original author(s) and the source, provide a link to the Creative Commons licence, and indicate if changes were made. The images or other third party material in this article are included in the article's Creative Commons licence, unless indicated otherwise in a credit line to the material. If material is not included in the article's Creative Commons licence and your intended use is not permitted by statutory regulation or exceeds the permitted use, you will need to obtain permission directly from the copyright holder. To view a copy of this licence, visit http://creativecommons.org/licenses/by/4.0/.

\section{References}

Agmon, T., \& Von Glinow, M. A. (1991). Technology transfer in international business. Oxford: Oxford University Press.

Arora, A., \& Fosfuri, A. (2000). Wholly owned subsidiary versus technology licensing in the worldwide chemical industry. Journal of International Business Studies, 31(4), 555-572.

Autio, E., \& Laamanen, T. (1995). Measurement and evaluation of technology transfer: Review of technology transfer mechanisms and indicators. International Journal of Technology Management, 10(7-8), 643-664.

Bakuli, D. L. (1994). Pitfalls in technology transfer: Kenya's construction industry. World Development, 22(10), 1609-1612.

Baranson, J. (1976). Technology exports can hurt us. Foreign Policy, 25, 180-194.

Battistella, C., De Toni, A. F., \& Pillon, R. (2016). Inter-organisational technology/knowledge transfer: A framework from critical literature review. The Journal of Technology Transfer, 41(5), 1195-1234.

Baughn, C. C., \& Osborne, R. N. (1989). Strategies for successful technological development. The Journal of Technology Transfer, 14(3-4), 5-13.

Bergström, M. (2004). Industrialised timber frame housing managing customisation, change, and information (Doctoral dissertation). Luleå, Sweden: Luleå University of Technology.

Berry, M. M., \& Taggart, J. H. (1994). Managing technology and innovation: A review. R\&D Management, 24(4), 341-353.

Björnfot, A. (2006). An exploration of lean thinking for multi-storey timber housing construction: Contemporary Swedish practices and future opportunities (Doctoral dissertation). Luleå, Sweden: Luleå University of Technology.

Bosman, R., \& Rotmans, J. (2016). Transition governance towards a bioeconomy: A comparison of Finland and the Netherlands. Sustainability, 8(10), 1017.

Bozeman, B. (2000). Technology transfer and public policy: A review of research and theory. Research Policy, 29(4-5), 627-655.

Bozeman, B., Rimes, H., \& Youtie, J. (2015). The evolving state-of-the-art in technology transfer research: Revisiting the contingent effectiveness model. Research Policy, 44(1), 34-49.

Brege, S., Nord, T., \& Stehn, L. (2017). Industriellt byggande i trä-nuläge och prognos mot 2025. Stockholm: Sveriges Träbyggnadskansli.

Bryman, A. (2003). Research methods and organisation studies. Abingdon: Routledge.

Burmeister, E., \& Aitken, L. M. (2012). Sample size: How many is enough? Australian Critical Care, 25(4), $271-274$. 
Chakrabarti, A. K. (1973). Some concepts of technology transfer: Adoption of innovations in organisational context. R\&D Management, 3(3), 111-120.

Chatterjee, P., \& Ireyes, H. (1981). Technology transfer: Implications for social work practice and social work education. International Social Work, 24(1), 14-22.

Chesnais, F. (1986). Science, technology and competitiveness. STI Review, 1(2), 85-129.

Contractor, F. J., \& Sagafi-Nejad, T. (1981). International technology transfer: Major issues and policy responses. Journal of International Business Studies, 12(2), 113-135.

Cooper, D. R., Schindler, P. S., \& Sun, J. (2006). Business research methods. New York: McGraw-Hill.

Cottrill, C. A., Rogers, E. M., \& Mills, T. (1989). Co-citation analysis of the scientific literature of innovation research traditions: Diffusion of innovations and technology transfer. Knowledge, 11(2), 181-208.

Cunningham, J. A., Menter, M., \& Young, C. (2017). A review of qualitative case methods trends and themes used in technology transfer research. The Journal of Technology Transfer, 42(4), 923-956.

De Laet, M., \& Mol, A. (2000). The Zimbabwe bush pump: Mechanics of a fluid technology. Social Studies of Science, 30(2), 225-263.

Deloitte. (2019). GPoC 2018. Global Powers of Construction. Infrastructure Department, Deloitte Madrid, Spain.

Devapriya, K. A. K., \& Ganesan, S. (2002). Technology transfer subcontracting in developing countries through. Building Research \& Information, 30(3), 171-182.

Dubois, A., \& Gadde, L. (2002). The construction industry as a loosely coupled system: Implications for productivity and innovation. Construction Management and Economics, 20(7), 621-631.

Elliott, R., Fischer, C. T., \& Rennie, D. L. (1999). Evolving guidelines for publication of qualitative research studies in psychology and related fields. British Journal of Clinical Psychology, 38(3), 215-229.

European Commission. (2020). Communication from the Commission to the European Parliament, the Council, the European Economic and Social Committee and the Committee of the Regions A new Circular Economy Action Plan For a cleaner and more competitive Europe.

Finfgeld, D. L. (2003). Metasynthesis: The state of the art-So far. Qualitative Health Research, 13(7), 893-904.

Fischer, W. A. (1976). Empirical approaches to understanding technology transfer. R\&D Management, $6(\mathrm{~S} 1), 151-157$.

Foster, G. M. (1962). Traditional cultures: And the impact of technological change. New York: Harper Publishing.

Ganesan, S., \& Kelsey, J. (2006). Technology transfer: International collaboration in Sri Lanka. Construction Management and Economics, 24(7), 743-753.

Gann, D. M. (1996). Construction as a manufacturing process? Similarities and differences between industrialised housing and car production in Japan. Construction Management and Economics, 14(5), $437-450$.

Geisler, E. (1993). Technology transfer: Toward mapping the field, a review, and research directions. The Journal of Technology Transfer, 18(3-4), 88-93.

Goodier, C. I., \& Pan, W. (2012). Briefing: Future trends in UK housebuilding. Municipal Engineer, 165(2), 65-67.

Guest, G., Bunce, A., \& Johnson, L. (2006). How many interviews are enough? An experiment with data saturation and variability. Field Methods, 18(1), 59-82.

Holstius, K. (1995). Cultural adjustment in international technology transfer. International Journal of Technology Management, 10(7-8), 676-686.

Höök, M. (2008). Lean culture in industrialised housing a study of timber volume element prefabrication (Doctoral dissertation). Luleå, Sweden: Luleå University of Technology.

Howells, J. (1996). Tacit knowledge. Technology Analysis \& Strategic Management, 8(2), 91-106.

$\mathrm{Hu}$, A. G., Jefferson, G. H., \& Jinchang, Q. (2005). R\&D and technology transfer: Firm-level evidence from Chinese industry. Review of Economics and Statistics, 87(4), 780-786.

Inkpen, A. C. (2000). Learning through joint ventures: A framework of knowledge acquisition. Journal of Management Studies, 37(7), 1019-1044.

Jansson, G. (2013). Platforms in industrialised housebuilding (Doctoral dissertation). Luleå, Sweden: Luleå University of Technology.

Jansson, G., Johnsson, H., \& Engström, D. (2014). Platform use in systems building. Construction Management and Economics, 32(1-2), 70-82.

Johnsson, H. (2013). Fånga det industriella byggandet. Luleå: Luleå University of Technology.

Johnsson, H., \& Meiling, J. H. (2009). Defects in offsite construction: Timber module prefabrication. Construction Management and Economics, 27(7), 667-681.

Kervin, J. B., \& Kervin, J. (1992). Methods for business research. New York: Harper Collins. 
Kirchberger, M. A., \& Pohl, L. (2016). Technology commercialisation: A literature review of success factors and antecedents across different contexts. The Journal of Technology Transfer, 41(5), 1077-1112.

Kiviniemi, A., \& Fischer, M. (2004). Requirements management interface to building product models. Espoo, Finland: VTT Technical Research Centre of Finland.

Koskela, L. (2000). An exploration towards a production theory and its application to construction. Espoo: VTT Technical Research Centre of Finland.

Koskela, L. (2003). Is structural change the primary solution to the problems of construction? Building Research \& Information, 31(2), 85-96.

Krugman, P. (1979). A model of innovation, technology transfer, and the world distribution of income. Journal of Political Economy, 87(2), 253-266.

Kumar, A., Motwani, J., \& Reisman, A. (1996). Transfer of technology: A classification of motivations. The Journal of Technology Transfer, 21(1-2), 34-42.

Lessing, J., \& Brege, S. (2015). Business models for product-oriented housebuilding companies-Experience from two Swedish case studies. Construction Innovation, 15(4), 449-472.

Lessing, J., Stehn, L., \& Ekholm, A. (2015). Industrialised housebuilding-Development and conceptual orientation of the field. Construction Innovation, 15(3), 378-399.

Levitt, H. M. (2018). How to conduct a qualitative meta-analysis: Tailoring methods to enhance methodological integrity. Psychotherapy Research, 28(3), 367-378.

Lorenz, A., Raven, M., \& Blind, K. (2017). The role of standardisation at the interface of product and process development in biotechnology. The Journal of Technology Transfer, 44, 1097-1133.

Lundahl, U., \& Skärvad, P. (2016). Utredningsmetodik för samhällsvetare och ekonomer. Lund: Studentlitteratur.

Ma, N., Roberts, R., Winefield, H., \& Furber, G. (2015). Utility of qualitative metasynthesis: Advancing knowledge on the wellbeing and needs of siblings of children with mental health problems. Qualitative Psychology, 2(1), 3.

Malik, K. (2002). Aiding the technology manager: A conceptual model for intra-firm technology transfer. Technovation, 22(7), 427-436.

Mansfield, E. (1968). Industrial research and technological innovation: An econometric analysis. The Economic Journal, 78(311), 676-679.

Mansfield, E. (1975). International technology transfer: Forms, resource requirements, and policies. The American Economic Review, 65(2), 372-376.

Mansfield, E., Romeo, A., Schwartz, M., Teece, D., Wagner, S., \& Brach, P. (1983). New findings in technology transfer, productivity and economic policy. Research Management, 26(2), 11-20.

Meiling, J. (2010). Continuous improvement and experience feedback in offsite construction: Timber-framed module prefabrication (Doctoral dissertation). Luleå, Sweden: Luleå University of Technology.

Merrill, R. S. (1972). The role of technology in cultural evolution. Social Biology, 19(3), 240-247.

Noh, H., \& Lee, S. (2019). Where technology transfer research originated and where it is going: A quantitative analysis of literature published between 1980 and 2015. The Journal of Technology Transfer, 44(3), 700-740.

Ofori, G. (1994). Construction industry development: Role of technology transfer. Construction Management and Economics, 12(5), 379-392.

Porter, M. E. (1980). Competitive strategy: Techniques for analysing industries and companies. New York: Free Press.

Reddy, N. M., \& Zhao, L. (1990). International technology transfer: A review. Research Policy, 19(4), 285-307.

Reisman, A. (1989). Technology transfer: A taxonomic view. The Journal of Technology Transfer, 14(34), 31-36.

Reisman, A. (2005). Transfer of technologies: A cross-disciplinary taxonomy. Omega, 33(3), 189-202.

Rogers, E. M. (2010). Diffusion of innovations. New York: Simon and Schuster.

Romney, A. K., Weller, S. C., \& Batchelder, W. H. (1986). Culture as consensus: A theory of culture and informant accuracy. American Anthropologist, 88(2), 313-338.

Saggi, K. (2002). Trade, foreign direct investment, and international technology transfer: A survey. The World Bank Research Observer, 17(2), 191-235.

Schreiber, R., Crooks, D., \& Stern, P. N. (1997). Qualitative meta-analysis. In J. M. Morse (Ed.), Completing a qualitative project: Details and dialogue (pp. 311-326). Thousand Oaks: Sage Publications.

Schumpeter, J. (1928). The instability of capitalism. The Economic Journal, 38(151), 361-386.

Siggelkow, N. (2007). Persuasion with case studies. Academy of Management Journal, 50(1), 20.

Stock, G. N., \& Tatikonda, M. V. (2000). A typology of project-level technology transfer processes. Journal of Operations Management, 18(6), 719-737. 
Teece, D. J. (1977). Technology transfer by multinational firms: The resource cost of transferring technological know-how. The Economic Journal, 87(346), 242-261.

Teece, D. J. (2004). Technology and technology transfer: Mansfieldian inspirations and subsequent developments. The Journal of Technology Transfer, 30(1-2), 17-33.

Teece, D. J. (2017). 5G mobile: Disrupting the automotive sector. Berkeley: UC Berkeley Haas School of Business.

Timulak, L. (2009). Meta-analysis of qualitative studies: A tool for reviewing qualitative research findings in psychotherapy. Psychotherapy Research, 19(4-5), 591-600.

Uusitalo, P., \& Lavikka, R. (2020). Overcoming path dependency in an industrialised housebuilding company through entrepreneurial orientation. Buildings, 10(3), 45.

Wahab, S. A., Rose, R. C., \& Osman, S. I. W. (2011). Measuring the effects of relationship quality and mutual trust on degree of inter-firm technology transfer in international joint venture. International Business Research, 4(3), 116-126.

Waroonkun, T., \& Stewart, R. A. (2008). Modeling the international technology transfer process in construction projects: Evidence from Thailand. The Journal of Technology Transfer, 33(6), 667-687.

Westerlund, L. (2009). Lindbäcks husbyggare med traditioner-Historien om familjeföretaget lindbäcks 1924-2009. Luleå: GTC.

Winch, G. (1998). Zephyrs of creative destruction: Understanding the management of innovation in construction. Building Research \& Information, 26(5), 268-279.

Yin, R. K. (2013). Case study research: Design and methods. Thousand Oaks: Sage Publications.

Zhao, L., \& Reisman, A. (1992). Toward meta research on technology transfer. IEEE Transactions on Engineering Management, 39(1), 13-21.

Publisher's Note Springer Nature remains neutral with regard to jurisdictional claims in published maps and institutional affiliations. 